\title{
Photoresponsive nanocapsulation of cobra neurotoxin and enhancement of its central analgesic effects under red light
}

This article was published in the following Dove Press journal:

International Journal of Nanomedicine

2 May 2017

Number of times this article has been viewed

\section{Qian Yang \\ Chuang Zhao \\ Jun Zhao \\ Yong Ye}

Department of Pharmaceutical Engineering, School of Chemistry and Chemical Engineering, South China University of Technology, Guangzhou, People's Republic of China
Correspondence: Yong Ye Department of Pharmaceutical Engineering, School of Chemistry and Chemical Engineering, South China University of Technology, 38I Wushan Road, Guangzhou 510640, People's Republic of China Tel +8620 87I I 0234

Email yeyong@scut.edu.cn
Abstract: Cobra neurotoxin (CNT), a peptide isolated from snake venom of Naja naja atra, shows central analgesic effects in our previous research. In order to help CNT pass through blood-brain barrier (BBB) and improve its central analgesic effects, a new kind of CNT nanocapsules were prepared by double emulsification with soybean lecithin and cholesterol as the shell, and pheophorbide as the photosensitizer added to make it photoresponsive. The analgesic effects were evaluated by hot plate test and acetic acid-induced writhing in mice. The CNT nanocapsules had an average particle size of $229.55 \mathrm{~nm}$, zeta potential of $-53.00 \mathrm{mV}$, encapsulation efficiency of $84.81 \%$ and drug loading of $2.98 \%$, when the pheophorbide content was $1 \%$ of lecithin weight. Pheophorbide was mainly distributed in outer layer of the CNT nanocapsules and increased the release of the CNT nanocapsules after $650 \mathrm{~nm}$ illumination. The central analgesic effects were improved after intraperitoneal injection of CNT at 25 and $50 \mu \mathrm{g} \cdot \mathrm{kg}^{-1}$ under $650 \mathrm{~nm}$ irradiation for $30 \mathrm{~min}$ in the nasal cavity. Activation of pheophorbide by red light generated reactive oxygen species which opened the nanocapsules and BBB and helped the CNT enter the brain. This research provides a new drug delivery for treatment of central pain.

Keywords: cobra neurotoxin, nanocapsules, photoresponsive, central analgesic effects, red light, drug delivery, photosensitizer

\section{Introduction}

Pain, a stress response or symptom caused by physical damage or disease, is closely associated with signal molecules in cells, including hormones, cytokines, neurotransmitters, lymphatic factors, growth factors and chemokines, which could change ion channels, the activities of relevant enzymes and gene expression. ${ }^{1,2}$ Nonsteriodal anti-inflammatory drugs (NSAIDs) or morphine-like painkillers are widely adopted as therapy for chronic pain in clinics, but NSAIDs can cause gastrointestinal damage such as hemorrhage and ulcer after long time use, ${ }^{3}$ and morphine-like drugs have undesirable complications and side effects such as addiction, tolerance, etc. ${ }^{4}$ Therefore, current analgesic research focus on natural medicines without tolerance, dependence and other side effects. ${ }^{5,6}$

Cobra neurotoxin (CNT), a short-chain peptide isolated from snake venom of Naja naja atra, has central analgesic effects and is appropriate for therapy of chronic pain, including cancer and neuropathic pain. ${ }^{7,8}$ But it is difficult to pass through the blood-brain barrier (BBB) due to the molecular weight of $7,000 \mathrm{Da},{ }^{9}$ and it has no ability of targeting central tissues after peripheral administration, which limits its practical use in clinics. Many methods of BBB permeation have been studied to help 
the macromolecules go through, such as conjugation with avidins, transport proteins or virus, ${ }^{10,11}$ but their stability and safety are unsolved yet.

Liposome has become a promising drug delivery system with the advantages of biocompatibility, biodegradability, ability to target specific cells or tissues, possibility of controlled release and protection against degradation of the drugs. ${ }^{12}$ The phospholipids bilayer of liposome could flexibly pass through the membrane of the cells via endocytosis and pinocytosis, which helps the drugs penetrate the cytoplasm. ${ }^{13}$ Furthermore, the liposome can be modified to be $\mathrm{pH}$ responsive, thermal responsive and enzymatic responsive in order to achieve drug release control. ${ }^{14}$

Liposome nanocapsules have the excellent capacity to transport hydrophilic compounds into cells in particle size of 100-300 nm due to their similarity with cell membrane, and they are usually prepared by film dispersion, membrane extrusion, emulsion evaporation and so forth. ${ }^{15}$ Among these methods, the double-emulsification method could achieve the controllability and flexibility of encapsulation for targeted delivery and release system. ${ }^{16}$

On the basis of our previous finding that the photosensitizers could assist the macromolecules permeate into the BBB but cause little injury, ${ }^{7}$ we designed a new kind of photoresponsive CNT nanocapsules by photosensitizer excitation of red light. We prepared it by the double-emulsification method and evaluated its central analgesic effects. Because red light can penetrate deeper tissues than ultraviolet and other visible light without side effects, ${ }^{16}$ it will achieve targeting the drug to central tissues by adjustment of BBB permeation and drug release.

\section{Materials and methods Chemicals}

Crude cobra venom was purchased from Jiangxi snake farm (Jiangxi, People's Republic of China), and its neurotoxin $(96 \%)$ was isolated and purified during our previous research. ${ }^{17}$ Pheophorbide (98\%) was extracted from silkworm feces in our laboratory. ${ }^{18}$ Soybean lecithin and cholesterol were bought from Guangzhou Qiyun Biotech Company (Guangzhou, People's Republic of China). Other chemicals were all analytical reagents without further purification and purchased from Qianhui Reagent Company (Guangzhou, People's Republic of China).

\section{Animals}

The experiments were performed on Kunming mice of weight $30 \pm 5 \mathrm{~g}$, supplied by the Experimental Animal Center of South Medical University (Guangzhou, People’s
Republic of China). The animals were housed under conditions of $25^{\circ} \mathrm{C} \pm 2{ }^{\circ} \mathrm{C}, 50 \% \pm 10 \%$ humidity with a $12 \mathrm{~h}$ light/dark cycle. Food and water were accessible ad libitum. The experiments were performed in accordance with the Chinese Guidelines for the use of laboratory animals and received approval (No 20160612) from the Animal Experimentation Ethic Committee of South China University of Technology.

\section{Isolation of CNT}

The CNT was isolated from venom of Naja naja atra according to Guo. ${ }^{17}$ Briefly, $1.5 \mathrm{~g}$ of crude venom was dissolved in $10 \mathrm{~mL}$ of $0.01 \mathrm{~mol} \cdot \mathrm{L}^{-1}$ acetate ammonia buffer ( $\left.\mathrm{pH} 5.0\right)$, passed through CM-AgroseCL-6B column $(10 \times 500 \mathrm{~mm})$ and then eluted by $0.1 \mathrm{~mol} \cdot \mathrm{L}^{-1}$ to $1.5 \mathrm{~mol} \cdot \mathrm{L}^{-1} \mathrm{NaCl}$ in acetate ammonia buffer ( $\mathrm{pH}$ 5.0) with linear gradient at $0.5 \mathrm{~mL} \cdot \mathrm{min}^{-1}$. The third peak was collected and further purified by Sephadex G-50 column $(10 \times 1,000 \mathrm{~mm})$ with elution by $0.01 \mathrm{~mol} \cdot \mathrm{L}^{-1}$ acetate ammonia buffer ( $\mathrm{pH} 5.0$ ) to $0.5 \mathrm{~mL} \cdot \mathrm{min}^{-1}$. The peak was collected, lyophilized and stored at $-20^{\circ} \mathrm{C}$.

\section{Preparation of photoresponsive CNT nanocapsules}

The CNT nanocapsules were prepared by a two-step emulsification procedure according to references with some modifications. ${ }^{16}$ First, soybean lecithin $(0.5 \mathrm{~g})$, cholesterol $(0.05 \mathrm{~g})$ and pheophorbide $(0 \%, 0.2 \%, 0.5 \%, 1 \%$ and $2 \%$ of lecithin weight) were dissolved in $10 \mathrm{~mL}$ of chloroform as phase A. CNT (0.02 g) was dissolved in $5 \mathrm{~mL}$ of phosphate buffer solution $\left(0.1 \mathrm{~mol} \cdot \mathrm{L}^{-1}\right.$ phosphate-buffered saline [PBS], $\mathrm{pH}=7.4$ ) as phase $\mathrm{B}$. Phase $\mathrm{B}$ was added dropwise to phase A with stirring at $6,000 \mathrm{r} \cdot \mathrm{min}^{-1}$ for $15 \mathrm{~min}$ to obtain the water/oil emulsion. Second, the water/oil emulsion was added dropwise to $5 \mathrm{~mL}$ of PBS $\left(0.1 \mathrm{~mol} \cdot \mathrm{L}^{-1}, \mathrm{pH}=7.4\right)$ and constantly stirred at $6,000 \mathrm{r} \cdot \mathrm{min}^{-1}$ for $15 \mathrm{~min}$ to form the water/oil/water emulsion. Finally, it was concentrated at $50^{\circ} \mathrm{C}$ for $2 \mathrm{~h}$ to remove chloroform by RE-52AA rotary vacuum evaporator (Shanghai Yarong Instrument Factory, Shanghai, People's Republic of China) and then dispersed in $25 \mathrm{~mL}$ of distilled water to pass through $0.45 \mu \mathrm{m}$ membrane. The CNT nanocapsules ( $0.7 \mathrm{~g}$ ) were obtained after lyophilization. Blank nanocapsules were prepared in the same process with $1 \%$ pheophorbide but no CNT was added.

\section{Determination of encapsulation efficiency (EE) and drug loading}

The sample $(10 \mathrm{mg})$ was dispersed in $10 \mathrm{~mL}$ of distilled water and centrifuged at $20,000 \mathrm{r} \cdot \mathrm{min}^{-1}$ in $4^{\circ} \mathrm{C}$ for $20 \mathrm{~min}$. 
The supernatant was kept as solution A, and the sediment was dispersed in $10 \mathrm{~mL}$ of distilled water and treated by ultrasonic for $5 \mathrm{~min}$ to break the nanocapsules, then filtered using a $0.22 \mu \mathrm{m}$ membrane to make solution $\mathrm{B}$. The concentration of CNT in solutions A and B was determined by HP 1200 highperformance liquid chromatography (Agilent Technologies Co., Santa Clara, CA, USA) in the following conditions: Column: TSK-GEL G2000SWXL (7.8×300 mm, $7 \mu \mathrm{m})$; mobile phase: $0.1 \mathrm{~mol} \cdot \mathrm{L}^{-1} \mathrm{PBS}\left(\mathrm{pH}=6.7\right.$ ) with $0.05 \% \mathrm{NaN}_{3}$; flow rate: $0.7 \mathrm{~mL} \cdot \mathrm{min}^{-1}$; temperature: $30^{\circ} \mathrm{C}$; injection volume: $20 \mu \mathrm{L}$; wavelength: $280 \mathrm{~nm} .{ }^{19} \mathrm{EE} \%$, was calculated as the percentage of (CNT content in solution $\mathrm{B}) /(\mathrm{CNT}$ content in solution $\mathrm{A}+$ solution $\mathrm{B}$ ); drug loading content (DLC\%) was calculated as the percentage of (CNT content in solution B)/(weight of the sample).

\section{Thermogravimetry and differential scanning calorimetry (DSC)}

Thermogravimetric analysis (TGA) and DSC were performed on an SDT-Q6000 thermogravimetric analyzer (TA Incorporated, New Castle, DE, USA). The CNT nanocapsules ( $4 \mathrm{mg}$ ) were weighed and heated from $30^{\circ} \mathrm{C}$ to $180^{\circ} \mathrm{C}$ at a rate of $5^{\circ} \mathrm{C} \cdot \mathrm{min}^{-1}$ under $100 \mathrm{~mL} \cdot \mathrm{min}^{-1}$ nitrogen flow.

\section{Measurement of particle size and zeta potential}

Particle size and zeta potential were determined in this research using a Nano-2S MDT-2 Malvern particle size analyzer (Malvern Instruments Limited, Malvern, UK). The sample of $5 \mathrm{mg}$ was dispersed in $10 \mathrm{~mL}$ of deionized water and then measured at $25^{\circ} \mathrm{C}$ to show a refractive index 1.33 . Data were calculated as the average of 5 repetitions.

\section{Morphological observation of the particles}

The CNT nanocapsules were diluted to a concentration of $0.5 \mu \mathrm{g} \cdot \mathrm{mL}^{-1}$ with deionized water, and then dropped on to a glass slide and observed by Y-2 Inverted Fluorescence Microscope (Shenzhen Aosvi Optical Instrument Company, Shenzhen, People's Republic of China) under white light and $415 \mathrm{~nm}$ excitation.

\section{Nanocapsule release test}

The release of CNT nanocapsules was measured by the dialysis diffusion method. ${ }^{20}$ The CNT nanocapsules $(5 \mathrm{mg}$ ) were dispersed in $10 \mathrm{~mL}$ of $\mathrm{pH} 7.4 \mathrm{PBS}\left(0.1 \mathrm{~mol} \cdot \mathrm{L}^{-1}\right)$, and put in the dialysis bag (molecular weight cutoff 10,000 Da), which was placed in the container with $100 \mathrm{~mL}$ of $\mathrm{pH} 7.4$ PBS $\left(0.1 \mathrm{~mol} \cdot \mathrm{L}^{-1}\right)$, stirred at $100 \mathrm{r} \cdot \mathrm{min}^{-1}$ and maintained at $37^{\circ} \mathrm{C} \pm 0.5^{\circ} \mathrm{C}$. After irradiation by $100 \mathrm{~mW}$ laser (Three Top Photoelectric Company, Dongguan, People's Republic of China) at $650 \mathrm{~nm}$ for 0,15 and $30 \mathrm{~min}, 1 \mathrm{~mL}$ of the solution was consecutively sampled at intervals of $1 \mathrm{~h}$, and the same volume of $0.1 \mathrm{~mol} \cdot \mathrm{L}^{-1} \mathrm{pH} 7.4 \mathrm{PBS}$ was supplemented at designated intervals. The concentration of CNT in the solution was determined by high-performance liquid chromatography for three repetitions, and the cumulative release was calculated during $12 \mathrm{~h}$ test.

\section{Hot plate test in mice}

The hot plate test in mice was performed in order to evaluate the response latencies according to Hayashi et al. ${ }^{21}$ The female mice were divided into 10 groups of 8 mice each: normal saline, blank nanocapsules, CNT nanocapsules containing $0.7 \%$ pheophorbide at high dose (HD) and low dose (LD) with and without nasal cavity irradiation at $650 \mathrm{~nm}$ for $30 \mathrm{~min}$. Based on effective and safe doses, ${ }^{22}$ the medicated groups of mice were given intraperitoneal injection of CNT at $50 \mu \mathrm{g} \cdot \mathrm{kg}^{-1}$, blank nanocapsules at $50 \mu \mathrm{g} \cdot \mathrm{kg}^{-1}$, CNT nanocapsules at $25 \mu \mathrm{g} \cdot \mathrm{kg}^{-1}$ (LD) and $50 \mu \mathrm{g} \cdot \mathrm{kg}^{-1}$ (HD). The control group was injected with the same volume of normal saline instead. The latency time for paw licking or jumping was recorded as pain threshold when mice were exposed to the hot plate surface at $55 \pm 0.5^{\circ} \mathrm{C}$. Basic pain threshold was determined before administration, and mice responses were recorded at $0.5,1,2$, 4, 6, 8, 12 and $18 \mathrm{~h}$ after administration. Pain inhibition was evaluated by pain threshold increase, which was calculated according to the following equation: Pain threshold increase $(\%)=\left(P_{t}-P_{0}\right) \times 100 / P_{0}$ where $P_{0}$ and $P_{t}$ separately represent basic pain threshold and pain threshold at " $t$ " time interval.

\section{Acetic acid-induced writhing test in mice}

Writhing in mice was induced according to the procedures described previously. ${ }^{23}$ The mice were divided into 10 groups with 8 mice in each. Each group had equal number of male and female mice. The groups and administration were the same as hot plate test. Afterward, the animals received nasal cavity irradiation at $650 \mathrm{~nm}$ for $30 \mathrm{~min}$ before intraperitoneal injection of acetic acid $(0.6 \%, \mathrm{v} / \mathrm{v})$ at $0.1 \mathrm{~mL} \cdot 10 \mathrm{~g}^{-1}$. The number of abdominal contraction was counted over a period of $30 \mathrm{~min}$ and expressed as writhing numbers. Antinociceptive activity was expressed as percent inhibition of writhing number in control animals.

\section{Statistical analysis}

Data were expressed as mean \pm standard deviation $(\bar{x} \pm s)$, and analyzed with SPSS17.0 software (IBM, Armonk, NY, USA). Significant tests among the groups were based on 
Table I Properties of the cobra neurotoxin nanocapsules with different concentrations of pheophorbide

\begin{tabular}{lllll}
\hline $\begin{array}{l}\text { Pheophorbide concentration } \\
\text { (\% lecithin weight) }\end{array}$ & $\begin{array}{l}\text { Encapsulation } \\
\text { efficiency (\%) }\end{array}$ & $\begin{array}{l}\text { Drug loading } \\
\text { content (\%) }\end{array}$ & $\begin{array}{l}\text { Average particle } \\
\text { size (nm) }\end{array}$ & $\begin{array}{l}\text { Zeta potential } \\
\text { (mV) }\end{array}$ \\
\hline I (blank nanocapsule) & $/$ & $/$ & $244.15 \pm 2.76$ & $-47.00 \pm 4.20$ \\
0 & $65.60 \pm 3.4$ & $2.30 \pm 0.12$ & $204.15 \pm 2.75$ & $-62.15 \pm 1.48$ \\
0.2 & $74.46 \pm 2.5$ & $2.61 \pm 0.09$ & $210.65 \pm 3.25$ & $-58.55 \pm 0.07$ \\
0.5 & $77.52 \pm 3.0$ & $2.72 \pm 0.11$ & $218.60 \pm 3.74$ & $-57.30 \pm 3.95$ \\
I & $84.81 \pm 2.0$ & $2.98 \pm 0.07$ & $229.55 \pm 0.49$ & $-53.00 \pm 0.56$ \\
2 & $68.92 \pm 3.6$ & $2.42 \pm 0.13$ & $234.35 \pm 2.21$ & $-50.50 \pm 1.56$ \\
\hline
\end{tabular}

Notes: Data are presented as mean \pm standard deviation $(n=5)$. All data show significant differences between treatments $(P<0.0 \mathrm{I})$.

Abbreviations: CNT, cobra neurotoxin; EE, encapsulation efficiency.

one-way analysis of variance and Student-Newman-Keuls test with $99 \%$ confidence limit and probability $P<0.01$.

\section{Results and discussion}

\section{Characteristics of the CNT nanocapsules}

The characteristics of the nanocapsules prepared by the double-emulsification method are shown in Table 1. The EE and DLC constantly increased until pheophorbide reached up to $1 \%$ content of lecithin weight, but decreased thereafter. The EE and DLC were $84.81 \pm 2.0 \%$ and $2.98 \pm 0.07 \%$. The average nanoparticle size and zetapotential were $229.55 \mathrm{~nm}$ and $-53.00 \mathrm{mV}$, respectively, suggesting that proper pheophorbide concentration is advantageous to compactness and stability of the nanocapsule, but excess pheophorbide was destructive. The size distribution and zeta potential are illustrated in Figure 1. The average size distribution in the range of 200-240 nm indicated that CNT was ideal for the nanocapsule preparation. The nanocapsules were homogeneous and stable because of appropriate negative charge repulsion.

Morphology of the nanocapsules was observed and photographed by fluorescence microscope. The images of CNT nanocapsules displayed good dispersity (Figure 2A) and sphericity with red fluorescence in borderline (Figure 2B). In the formulation of CNT nanocapsules, only pheophorbide had red fluorescence under the illumination at $415 \mathrm{~nm}$.

A

Size distribution by intensity
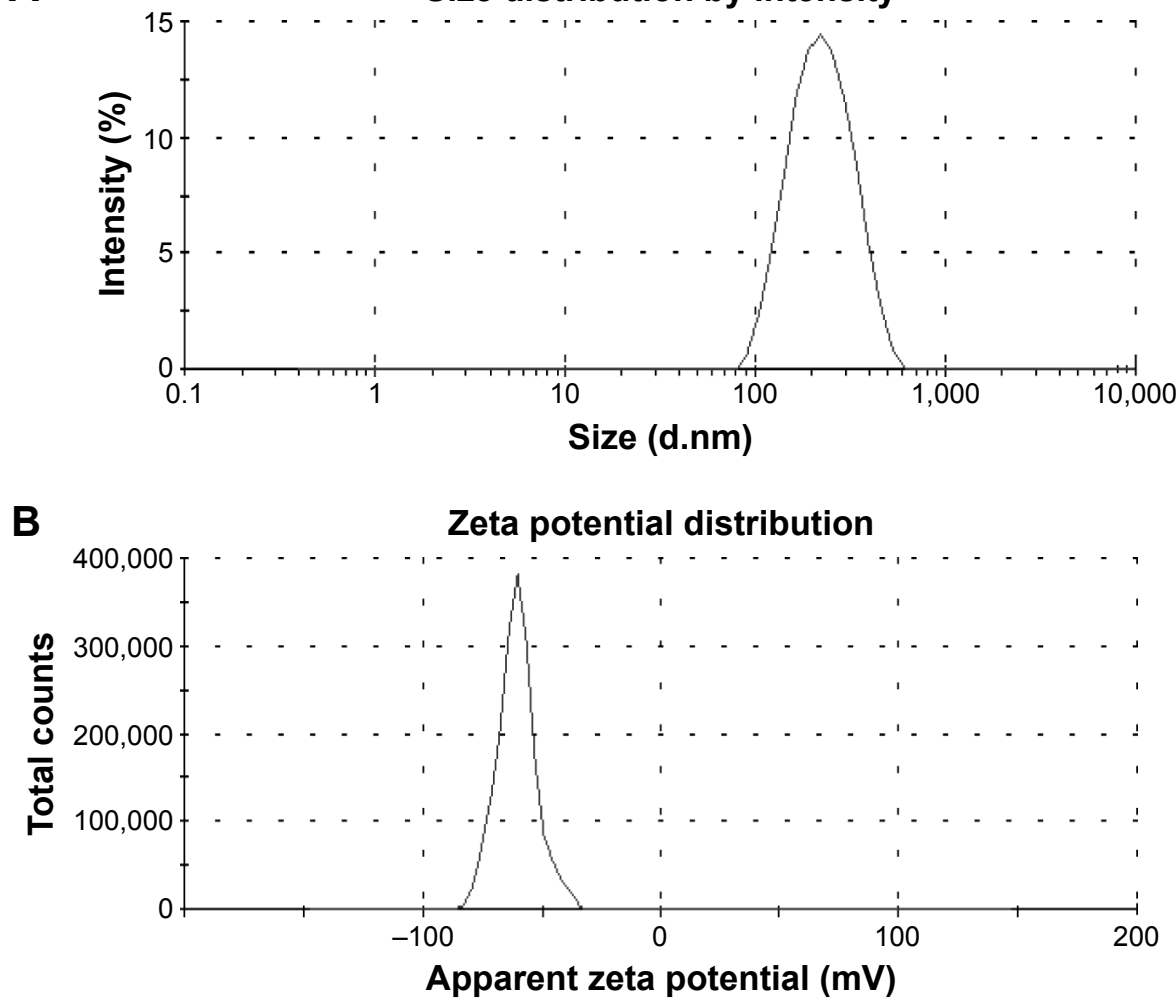

Figure I Size distribution (A) and zeta potential (B) of cobra neurotoxin nanocapsules. 

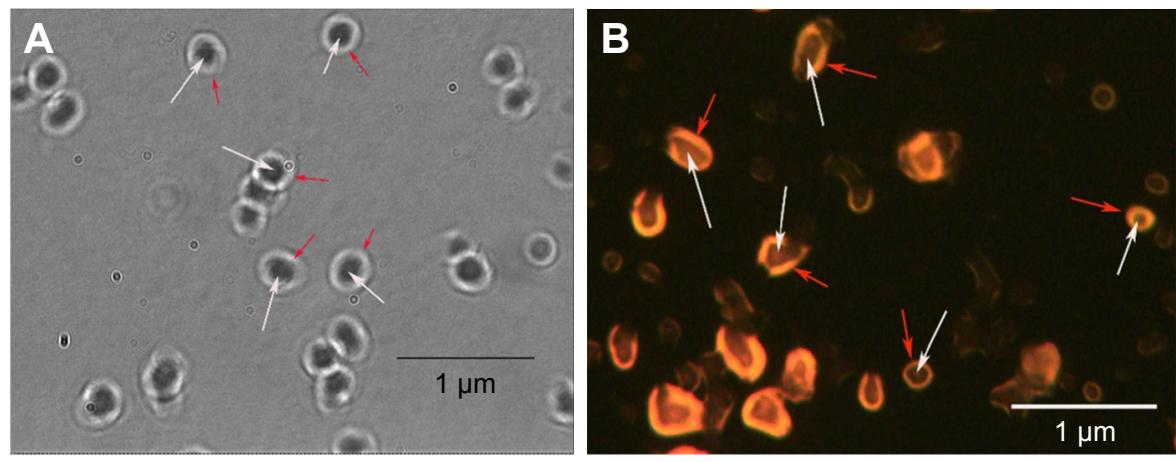

Figure 2 Photograph under white light $(\mathbf{A})$ and fluorescence photograph under $415 \mathrm{~nm}$ light excitation (B) of the CNT nanocapsules by microscope at I,000× amplification. Red arrows represent pheophorbide in the outer shell and white arrows represent CNT in the inner core of the nanocapsules.

Abbreviation: CNT, cobra neurotoxin.

It indicated that pheophorbide is mainly distributed in the outer shell of the nanocapsules, and water soluble CNT is encapsulated by a bilayered structure of lecithin and cholesterol without molecular agglomeration.

TGA and DSC were applied as a simple method to determine the thermostability of the nanocapsules. As shown in Figure 3, the nanocapsules exhibited $<5 \%$ weight loss at $80^{\circ} \mathrm{C}$ in TGA curve and a single endothermic melting peak at $78^{\circ} \mathrm{C}$ in the DSC curve. It confirms that $\mathrm{CNT}$ nanocapsules are stable for application below that temperature.

The pheophorbide, a porphyrin isolated from excrement of silkworm, is hydrophobic with a single hydrophilic carboxyl group. Hence, a certain amount of pheophorbide can combine with lecithin and enhance the stability of hydrophobic block in the nanocapsules, but excess pheophorbide vastly impedes tight junction of lecithin, leading to the decrease in DLC and EE. ${ }^{24}$ CNT, a water-soluble peptide, can change the distribution of negative and positive charges of polarity zones via ion-dipole interaction on the surface of

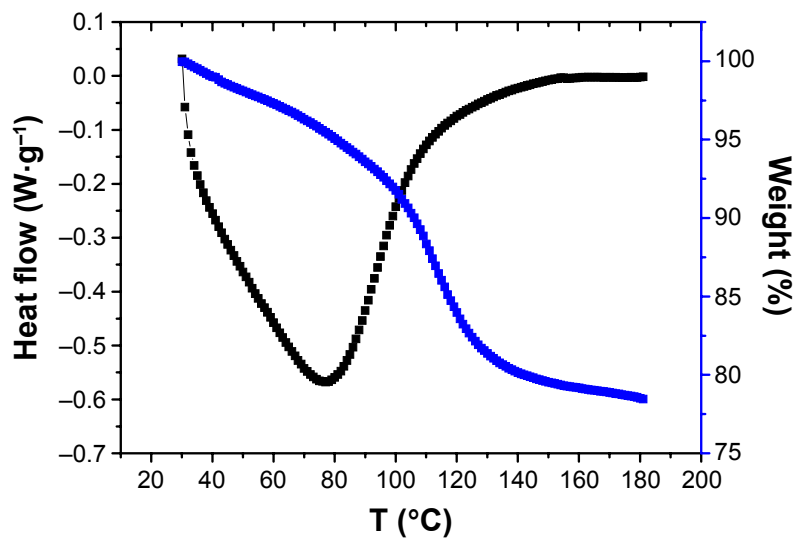

Figure 3 Differential scanning calorimetric and thermogravimetric chart of cobra neurotoxin nanocapsules.

Note: The black line represents heat flow; the blue line represents weight percentage. the nanocapsules and hinder the aggregation and formation of larger particles. ${ }^{25}$ The average size of CNT nanocapsules is smaller than blank nanocapsules due to interfacial interaction between CNT and lecithin. The positive charge of CNT can attract the negative charge of lecithin, making the nanocapsules compact and small.

\section{Photoresponsiveness of the CNT nanocapsules}

The cumulative release curves of CNT nanocapsules were significantly different as based on various illuminating time as shown in Figure 4. The release rate could reach $67.35 \%$ and $82.17 \%$ at the interval of $12 \mathrm{~h}$ with $15 \mathrm{~min}$ and $30 \mathrm{~min}$ irradiation, respectively, but only $30.11 \%$ in the same time interval without irradiation. The results demonstrate that CNT nanocapsules release slowly, remain stable under no illumination and have photoresponsiveness under $650 \mathrm{~nm}$ irradiation.

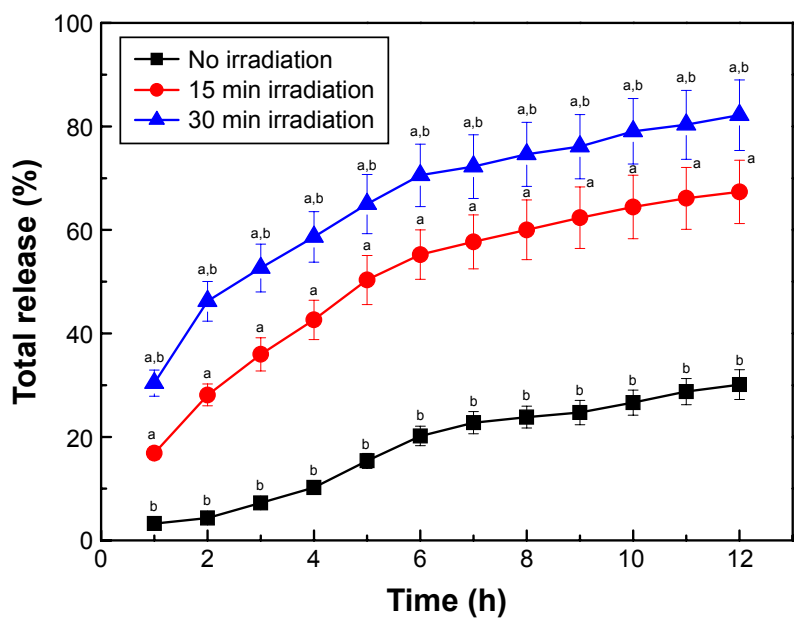

Figure 4 Total release ratio of the cobra neurotoxin nanocapsules at different times of irradiation at $650 \mathrm{~nm}$.

Notes: Data were presented as mean \pm standard deviation in 3 repetitions. (a) $P<0.0$ I, compared with no irradiation; (b) $P<0.0$ I, compared with 15 min irradiation. 
Currently, most photoresponsive formulas utilize azobenzene as the photosensitive agent and require excitation by ultraviolet light (UV), but UV light is easily absorbed by tissues and harms the cells. ${ }^{26}$ On the contrary, tissues absorb less red light, and it can penetrate deeper into the tissues without harming them. Pheophorbide, an effective photosensitizer in photodynamic therapy, could generate singlet oxygen excited by red light. ${ }^{27}$ Furthermore, the cell membrane composed of phospholipids linked by phosphodiester bonds, could be broken by reactive oxygen species. ${ }^{28}$ Therefore, the photoactivated release mechanism of CNT from the nanocapsule is attributed to the breakage of lecithin's phosphodiester bonds by pheophorbide-produced singlet oxygen.

\section{Analgesic effects of the CNT nanocapsules}

The hot plate test was a common model of thermal-induced nociception, which was used to evaluate the central action..$^{7,29}$ Hot plate test in mice indicated that the latency of response gradually increased with time in the medicated groups (Figure 5). There were obvious differences among the groups of CNT nanocapsules with and without irradiation. The medicated group with CNT nanocapsule plus $30 \mathrm{~min}$ illumination not only had greater pain threshold than others but also reached the maximum at interval quickly at $6 \mathrm{~h}$. This suggests that irradiation of CNT nanocapsule by red light expedites the permeation of CNT across the $\mathrm{BBB}$ into the brain and promotes its central analgesic activity.

Acetic acid-induced writhing test in mice also showed that CNT group could inhibit the writhing number of
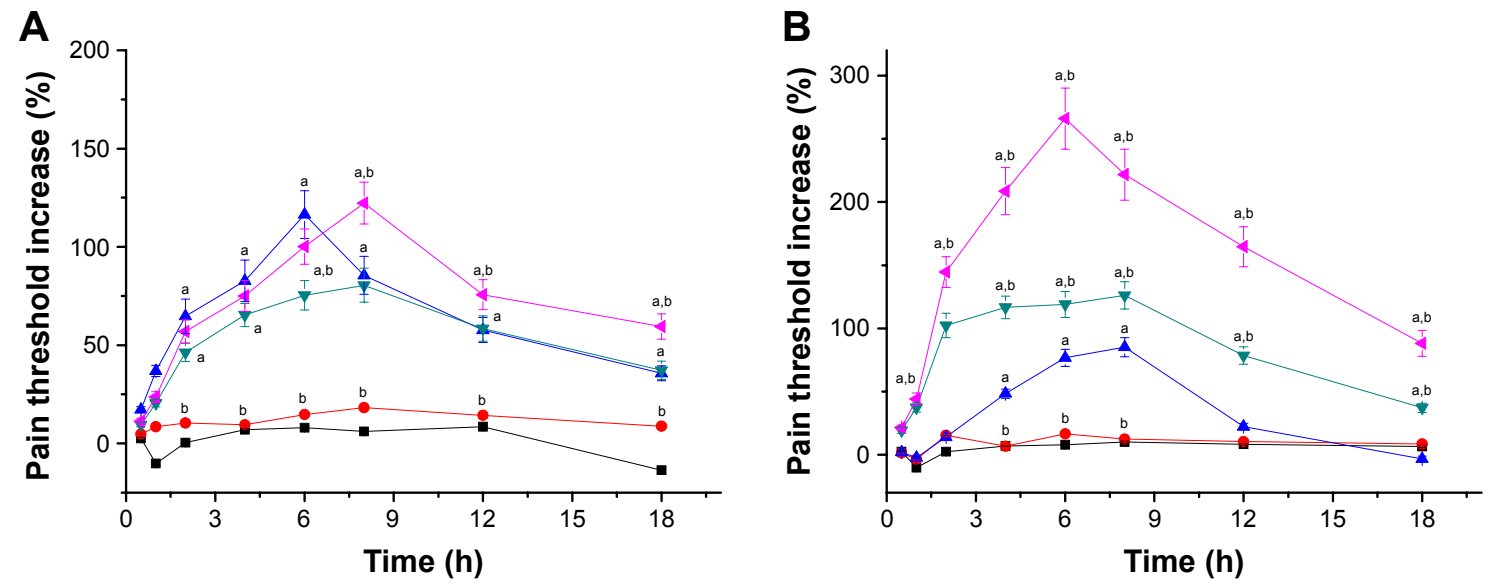

$\multimap$ Normal saline $\longrightarrow$ Blank nanocapsule $\neg$ CNT $\neg$ CNT nanocapsule LD $\leftarrow$ CNT nanocapsule HD

Figure 5 Analgesic effects of the CNT nanocapsules on mice by hot plate test. Mice groups were administered a dose of $50 \mu \mathrm{g} \cdot \mathrm{kg}^{-1}$ of $\mathrm{CNT}$ and blank nanocapsules ip mice groups were also administered CNT nanocapsules LD and HD $25 \mu \mathrm{g} \cdot \mathrm{kg}^{-1}$ and $50 \mu \mathrm{g} \cdot \mathrm{kg}^{-1}$ ip, respectively. (A) No illumination, (B) 30 min illumination of nasal cavity by $100 \mathrm{~mW} 650 \mathrm{~nm}$ laser. Data were represented as $\bar{x} \pm s, \mathrm{n}=8$. (a) $P<0.0$, compared with blank nanocapsule group; (b) $P<0.01$, compared with CNT group.

Abbreviations: CNT, cobra neurotoxin; HD, high dose; ip, intraperitoneal; LD, low dose.

mice, but no significant $(P>0.05)$ changes took place during illumination (Table 2). Only CNT nanocapsule group had significant $(P<0.01)$ changes with dose dependence in writhing number after illumination. It suggests that CNT nanocapsules with illumination can cause an analgesic effect.

The two pain models in animals have different mechanisms. Hot plate test is a model of heat nociception, which is mainly related to central action. ${ }^{30}$ Acetic acid-induced writhing test is a model of chemical nociception, which has combined action on both central and peripheral nerves. ${ }^{31}$ The CNT nanocapsules are effective in both pain models, suggesting both central and peripheral analgesic effects, but act with more power on the central nervous system. It proves that the red light illumination of CNT nanocapsules enhances its central analgesic effects. Nasal cavity irradiation is convenient and causes no injury. It is reported that drugs absorbed by nasal mucosa can be easily transported to the brain, ${ }^{32}$ and intranasal route is the alternative route to parenteral administration. ${ }^{33}$ Nasal cavity irradiation helps CNT go across the BBB and brings better central analgesic effects.

\section{Conclusion}

The CNT nanocapsules made by double emulsification of soybean lecithin, cholesterol, CNT and pheophorbide with a $1 \%$ lecithin concentration have the maximum $\mathrm{EE}$ and DLC of CNT. The pheophorbide is well scattered in the outer shell, and CNT is encapsulated in the nanocapsules with higher stability. The release of CNT from the 
Table 2 Writhing number of mice before and after illumination

\begin{tabular}{|c|c|c|c|c|c|}
\hline $\begin{array}{l}\text { Groups without } \\
\text { illumination }\end{array}$ & $\begin{array}{l}\text { Writhing } \\
\text { number }\end{array}$ & Inhibition/\% & $\begin{array}{l}\text { Groups with } \\
\text { illumination }\end{array}$ & $\begin{array}{l}\text { Writhing } \\
\text { number }\end{array}$ & Inhibition/\% \\
\hline Normal saline & $62.2 \pm 5.4$ & I & Normal saline & $65.7 \pm 6.4$ & I \\
\hline Blank nanocapsule & $64.3 \pm 6.7$ & -3.4 & Blank nanocapsule & $63.7 \pm 6.7$ & 3.0 \\
\hline CNT & $46.8 \pm 5.3$ & 24.8 & CNT & $45.8 \pm 6.2$ & 30.3 \\
\hline CNT nanocapsule LD & $42.5 \pm 4.8$ & 31.7 & CNT nanocapsule LD & $19.4 \pm 3.6 * *$ & 70.5 \\
\hline CNT nanocapsule HD & $35.7 \pm 4.6$ & 42.6 & CNT nanocapsule HD & $13.7 \pm 3.4^{* *}$ & 79.1 \\
\hline
\end{tabular}

Notes: Mice groups were administered CNT and blank nanocapsules at dose of $50 \mu \mathrm{g} \cdot \mathrm{kg}^{-1}$ ip; mice groups were also administered CNT nanocapsules LD and HD at $25 \mu \mathrm{g} \cdot \mathrm{kg}^{-1}$ and $50 \mu \mathrm{g} \cdot \mathrm{kg}^{-1}$ ip, respectively. Illumination of the nasal cavity was performed by $100 \mathrm{~mW} 650 \mathrm{~nm}$ laser for $30 \mathrm{~min}$. Data were represented as $\bar{x} \pm s, \mathrm{n}=8$. $* * \mathrm{P}<0.0 \mathrm{I}$, compared with corresponding groups without illumination.

Abbreviations: CNT, cobra neurotoxin; HD, high dose; ip, intraperitoneal; LD, low dose.

nanocapsules is significantly enhanced by $650 \mathrm{~nm}$ irradiation. The central analgesic effect of CNT nanocapsules improves when the nasal cavity is irradiated by red light. The mechanism is related to excitation of pheophorbide by red light and production of singlet oxygen to increase CNT release from the nanocapsules, which enter the brain. This research provides a new type of red light-responsive nanopreparation of CNT, which is more effective for treatment of central pain.

\section{Acknowledgments}

The authors are grateful to the staff at South China University of Technology for the data analysis they provided. Financial support from the Guangzhou and Guangdong Scientific Plan Projects (Grant Nos 1563000123 and 2016B090918086, respectively) is also acknowledged.

\section{Disclosure}

The authors report no conflicts of interest in this work.

\section{References}

1. Ma W, Quirion R. The ERK/MAPK pathway, as a target for the treatment of neuropathic pain. Expert Opin Ther Targets. 2005;9(4):699-713.

2. Smits H, Kleef MV, Honig W, Gerver J, Gobrecht P, Joosten EA. Spinal cord stimulation induces c-Fos expression in the dorsal horn in rats with neuropathic pain after partial sciatic nerve injury. Neurosci Lett. 2009;450(1):70-73.

3. Pellicano R. Gastrointestinal damage by non-steroidal anti-inflammatory drugs: updated clinical considerations. Minerva Gastroenterol Dietol. 2014;60(4):255-261.

4. Chung YC, Tsou MY, Chen HH, Lin JG, Yeh ML. Integrative acupoint stimulation to alleviate postoperative pain and morphine-related side effects: a sham-controlled study. Int J Nurs Stud. 2014;51(3):370-378.

5. Bednarczyk-Cwynar B, Wachowiak N, Szulc M, et al. Strong and longlasting antinociceptive and anti-inflammatory conjugate of naturally occurring oleanolic acid and aspirin. Front Pharmacol. 2016;7:202.

6. Zhai C, Liu Q, Zhang Y, et al. Identification of natural compound carnosol as a novel TRPA1 receptor agonist. Molecules. 2014;19(11): 18733-18746.

7. Ye Y, Li Y, Fang F. Opening of brain blood barrier induced by red light and central analgesic improvement of CNT.J Photochem Photobiol B. 2014;134:16-22.
8. Pla D, Paiva OK, Sanz L, et al. Preclinical efficacy of Australian antivenoms against the venom of the small-eyed snake, Micropechisikaheka, from Papua New Guinea: an antivenomics and neutralization study. J Proteomics. 2014;110:198-208.

9. Lu Q, Meng Q, Li D, et al. Comparative study of three short-chain neurotoxins from the venom of Najakaouthia (Yunnan, China). J Nat Toxins. 2002;11(3):221-229.

10. Garcel A, Fauquette W, Dehouck MP, Crance MP, Favier AL. Vaccinia virus-induced smallpox postvaccinal encephalitis in case of blood-brain barrier damage. Vaccine. 2012;30(7):1397-1405.

11. Krizbai IA, Nyúl-Tóth Á, Bauer HC, et al. Pharmaceutical targeting of the brain. Curr Pharm Des. 2016;22(35):5442-5462.

12. Mallick S, Choi JS. Liposomes: versatile and biocompatible nanovesicles for efficient biomolecules delivery. J Nanosci Nanotechnol. 2014;14(1):755-765.

13. Li Z, Liu M, Wang H, Du S. Increased cutaneous wound healing effect of biodegradable liposomes containing madecassoside: preparation optimization, in vitro dermal permeation, and in vivo bioevaluation. Int J Nanomedicine. 2016;11:2995-3007.

14. Wang T, Deng Y, Geng Y, Gao Z, Zou J, Wang Z. Preparation of submicron unilamellar liposomes by freeze-drying double emulsions. Biochim Biophys Acta. 2006;1758(2):222-231.

15. Vauthier C, Bouchemal K. Methods for the preparation and manufacture of polymeric nanoparticles. Pharm Res. 2009;26(5):1025-1058.

16. Seo HJ, Kim JC. Characteristics and photo-responsive release property of liposome containing 7-acetoxy coumarin. J Nanosci Nanotechnol. 2011;11(11):10262-10270.

17. Guo Y. Regulation of Cerebral Permeation Activated by Photosensitizers from TCM and Analgesia Mechanism of Peptides from Snake Venom [dissertation]. Guangzhou: South China University of Technology. 2014.

18. Gao HG, Ye Y, Hu AX. Study on fluorescence properties of pheophorbide A. Chin J New Drug. 2007;16(23):1965-1967.

19. Fang F. Light Response Neurotoxin Nanocapsule Preparation and its Analgesic Mechanism [dissertation]. Guangzhou: South China University of Technology. 2015.

20. Fan Y, Liu J, Wang D, et al. The preparation optimization and immune effect of epimedium polysaccharide-propolis flavone liposome. Carbohydr Polym. 2013;94(1):24-30.

21. Hayashi T, Katsuyama S, Orito T, Suzuki T, Sakurada S. Antinociceptive effect of tebanicline for various noxious stimuli-induced behaviours in mice. Neurosci Lett. 2016;638:46-50.

22. Ständker L, Harvey AL, Fürst S, et al. Improved method for the isolation, characterization and examination of neuromuscular and toxic properties of selected polypeptide fractions from the crude venom of the Taiwan cobra Naja naja atra. Toxicon. 2012;60(4):623-631.

23. Bukhari IA, Gilani AH, Meo SA, Saeed A. Analgesic, anti-inflammatory and anti-platelet activities of Buddleja crispa. BMC Complement Altern Med. 2016;16:79.

24. Ye Y, Xing H, Li Y. Nanoencapsulation of the sasanquasaponin from Camellia oleifera, its photo responsiveness and neuroprotective effects. Int J Nanomedicine. 2014;9:4475-4484. 
25. Zhang $\mathrm{S}$, Uludağ $\mathrm{H}$. Nanoparticulate systems for growth factor delivery. Pharm Res. 2009;26(7):1561-1580.

26. Lau YA, Henderson BL, Lu J, Ferris DP, Tamanoi F, Zink JI. Continuous spectroscopic measurements of photo-stimulated release of molecules by nanomachines in a single living cell. Nanoscale. 2012; 4(11):3482-3489.

27. Xodo LE, Rapozzi V, Zacchigna M, Drioli S, Zorzet S. The chlorophyll catabolite pheophorbide a as a photosensitizer for the photodynamic therapy. Curr Med Chem. 2012;19(6):799-807.

28. Kornfeld OS, Hwang S, Disatnik MH, Chen CH, Qvit N, Mochly-Rosen D. Mitochondrial reactive oxygen species at the heart of the matter: new therapeutic approaches for cardiovascular diseases. Circ Res. 2015;116(11): 1783-1799.

29. Ghildiyal S, Gautam MK, Joshi VK, Goel RK. Analgesic and hypnotic activities of Laghupanchamula: a preclinical study. Int J Ayu Res. 2014; 35(1):79-84.
30. Kokotos G, Six DA, Loukas V, et al. Inhibition of group IVA cytosolic phospholipase $\mathrm{A}(2)$ by novel 2-oxoamides in vitro, in cells, and in vivo. J Med Chem. 2004;47(14):3615-3628.

31. Derardt R, Jougney S, Delevalcee F, Falhout M. Release of prostaglandins $\mathrm{E}$ and $\mathrm{F}$ in analgogenic reaction and its inhibition. Eur J Pharmacol. 1980;61(1):17-24.

32. Pardeshi CV, Belgamwar VS. Direct nose to brain drug delivery via integrated nerve pathways bypassing the blood-brain barrier: an excellent platform for brain targeting. Expert Opin Drug Deliv. 2013;10(7):1-16.

33. Turker S, Onur E, Ozer AY. Nasal route and drug delivery systems. Pharm World Sci. 2004;26(3):137-142.
International Journal of Nanomedicine

\section{Publish your work in this journal}

The International Journal of Nanomedicine is an international, peerreviewed journal focusing on the application of nanotechnology in diagnostics, therapeutics, and drug delivery systems throughout the biomedical field. This journal is indexed on PubMed Central, MedLine, CAS, SciSearch ${ }^{\circledR}$, Current Contents ${ }^{\circledR} /$ Clinical Medicine,

\section{Dovepress}

Journal Citation Reports/Science Edition, EMBase, Scopus and the Elsevier Bibliographic databases. The manuscript management system is completely online and includes a very quick and fair peer-review system, which is all easy to use. Visit http://www.dovepress.com/ testimonials.php to read real quotes from published authors. 